\title{
Morphology and Kinetics of Discontinuous Precipitation and Dissolution in an Fe-8.5Al-27Mn-1.0Si-0.92C Alloy
}

\author{
SHIH-YING CHANG, SHIUAN-SHENG WANG, LUNG-CHUAN TSAO, \\ and TUNG-HAN CHUANG
}

The morphology and growth kinetics of discontinuous precipitation (DP) and discontinuous dissolution (DD) in an Fe-8.5Al-27Mn-1.0Si-0.92C alloy are investigated. The results indicate that the solidsolution-treated austenite phase decomposes into lamellar DP after aging at temperatures ranging from 900 to $1050 \mathrm{~K}$. After the specimens of a preaged DP structure go through further aging at temperatures ranging from 1118 to $1173 \mathrm{~K}$, the lamellar DP falls into dissolution because of the DD reaction. The lamellar spacings of the DP structure, as well as the reaction-front migration rates during DP and DD reactions, are measured. Based on Aaronson and Liu's simplified kinetics model, the grain-boundary diffusivities are estimated. They are found to be slightly lower than the grain-boundary diffusion data of $\mathrm{Mn}$ in $\mathrm{Fe}$ and $\mathrm{Fe}$ in $\mathrm{Fe}$ as reported by Aaronson and Liu.

\section{INTRODUCTION}

DISCONTINUOUS precipitation (DP) is a solid-state reaction in which an initially homogeneous, supersaturated solid solution is decomposed into a lamellar two-phase microstructure in the region behind the migrating reaction front. ${ }^{[1,2]}$ This reaction starts preferentially at a large-angle grain boundary. By heating the alloy after partial decomposition through DP to near or above the solvus temperature, the lamellar DP will dissolve under a discontinuous dissolution (DD) reaction, while the reaction front between the DP and the matrix will migrate backwards as well. ${ }^{[2,3,4]}$ Owing to merits, such as high strength, high corrosion and oxidation resistance, and low cost, the FeAlMn alloy has been considered as a promising substitute alloy for the more expensive austenite stainless steels. ${ }^{[5]}$ In order to attain optimal alloy design of the FeAlMn system, it is necessary to understand its phase transformations under various aging processes. ${ }^{[6,7]}$ Related investigations have been extensively conducted; among which, the grain-boundary precipitation in this alloy system has been most exhaustively studied. ${ }^{[4-14]}$ In a fully austenitized Fe-9Al-9.5Mn0.96C-6.77Ni, James found a DP of (ferrite + carbide) phases after aging at $873 \mathrm{~K} \cdot{ }^{[8]}$ The precipitated carbide was a mixed compound, $(\mathrm{FeMn})_{3} \mathrm{AlC}$, with a cubic structure.

The result was confirmed by Krivonogov et al. in a study of the Fe-9Al-29Mn-0.9C alloy, ${ }^{[9]}$ which showed that the quenching austenite of this alloy would decompose at temperatures below $1023 \mathrm{~K}$, first, into a coherent metastable continuous precipitation ( $\kappa^{\prime}$ phase $\mathrm{Fe}_{3} \mathrm{AlC}_{0.66}$ ), which possessed an ordered fcc-perovskite-type structure, and was oriented in the $\langle 100\rangle$ crystallographic direction. After prolonged aging, a DP of $\alpha$ (ferrite) $+\beta$-Mn $+\kappa$ occurred at the austenite grain boundaries. The $\kappa$ phase was identified as a coarse $(\mathrm{Fe}, \mathrm{Mn})_{3} \mathrm{AlC}_{x}$ carbide. The initially formed $\kappa^{\prime}$ precipitates grew simultaneously in the austenite grains and

SHIH-YING CHANG and LUNG-CHUAN TSAO, Post-doctorates, and TUNG-HAN CHUANG, Professor, are with the Department of Materials Science and Engineering, National Taiwan University, 1 Roosevelt Road, Sec. 4, Taipei 106, Taiwan. SHIUAN-SHENG WANG, Lecturer, is with the Department of Mechanical Engineering, De-Lin Institute of Technology, Tu-Cheng, Taipei 236, Taiwan. Contact e-mail: tunghan@ccms.ntu.edu.tw Manuscript submitted July 3, 2001. were transformed into incoherent coarse particles of the $\kappa$ phase $(\mathrm{Fe}, \mathrm{Mn})_{3} \mathrm{AlC}_{x}$.

At higher temperatures ranging from 1023 to $1123 \mathrm{~K}$ and already in the initial stage of decomposition, the $\kappa$ phase $(\mathrm{Fe}$, $\mathrm{Mn})_{3} \mathrm{AlC}_{x}$ precipitated preferentially at grain boundaries. As the aging time increased, the DP formed at grain boundaries was $(\alpha+\kappa)$ phases in the absence of the $\beta$-Mn phase. Similar structural changes were noted by Storchak and Drachinskaya ${ }^{[10]}$ in an FeAlMn single-crystal specimen with the same composition as the polycrystalline alloy employed by Krivonogov et al. The existence of a $\beta$-Mn phase in FeAlMn alloys after prolonged aging at lower temperatures $($ e.g., $823 \mathrm{~K})$ has also been investigated by Sato et al. ${ }^{[11]}$ Duh et al. ${ }^{[12]}$ and Hwang et al. ${ }^{[13]}$ However, Chao and $\operatorname{Han}^{[14,15]}$ indicated that the $\beta$-Mn phase coexisted with the DP $(\alpha+$ $\kappa)$ on grain boundaries in the rapidly solidified FeAlMn alloys. For a conventionally prepared, cold-rolled, and subsequently austenitized Fe-8.8Al-31.5Mn-1.36C alloy, no $\beta$ $\mathrm{Mn}$ phase was found even after prolonged aging at $823 \mathrm{~K}$ for 317 hours. In the other works of Chao et al. about the transmission electron microscopy (TEM) observations of grain-boundary precipitation in FeAlMn alloys ${ }^{[16-19]}$ they also reported that the $\beta$-Mn phase did not coexist with the $\kappa$ phase on grain boundaries. The authors offered an explanation by suggesting that the precipitation of the $\kappa$ phase with a very high Mn content (46.5 pct) inhibited the presence of the Mn-rich $\beta$-Mn phase. ${ }^{[18,19]}$ Via selected area diffraction in the TEM, Chao et al. further revealed that the DP of FeAlMn alloys consisted of a $\kappa$ phase and an ordered $\mathrm{DO}_{3}$ phase rather than the $(\alpha+\kappa)$ phases, as reported in some earlier works. ${ }^{[8-15]}$

In contrast to many efforts exerted over phase identifications of the grain-boundary precipitation in FeAlMn alloys, the morphology of such discontinuous precipitates has scarcely been discussed. In particular, the growth kinetics of DP in this alloy has never been studied. Furthermore, the morphology and kinetics of DD in FeAlMn alloys have never been reported. In fact, even though the DP has been noted in over 200 alloy systems, ${ }^{[1]}$ most of them are binary or simple ternary alloys. Likewise, all previous studies on DD have dealt with binary alloys, and a technical alloy made up of multiple components has not yet been investigated. 
In this study, the morphology of DP and DD reactions of the Fe-8.5Al-27Mn-1.0Si-0.92C alloy is observed through optical microscopy (OM) and scanning electron microscopy (SEM). The growth velocities and the lamellar spacings of the discontinuous precipitates in this alloy are also measured in the temperature range from 900 to $1050 \mathrm{~K}$. Because of the complexity of alloy components, most kinetics models ${ }^{[20-26]}$ of DP and DD are inapplicable. The results are, thus, analyzed by applying the simplified Aaronson and Liu theory. ${ }^{[27]}$ In addition, the backward migration rates of the reaction front accompanying the DD reaction of this alloy have been ascertained in the temperature range between 1118 and $1173 \mathrm{~K}$, and a kinetics analysis similar to that of the DP reaction has been performed.

\section{EXPERIMENTAL}

The alloy, Fe-8.5Al-27Mn-1.0Si-0.92C (wt pct), was prepared from electrolytic iron $(2 \mathrm{~N})$, electrolytic manganese $(3 \mathrm{~N})$, aluminum $(4 \mathrm{~N})$, high purity silicon, and carbon under air-induction melting. Homogenized at $1473 \mathrm{~K}$ for 12 hours, the ingot was then hot forged to a $25-\mathrm{mm}$-thick slab and cut into $10 \times 10 \times 3 \mathrm{~mm}$ specimens. Afterwards, the specimens were encapsulated in quartz tubes $\left(1.3 \times 10^{-1} \mathrm{~Pa}\right)$ under vacuum, solution heat-treated at $1273 \mathrm{~K}$ for 8 hours, while the water-quenched condition was a complete austenite phase with a grain size of about $240 \mu \mathrm{m}$. The as-quenched samples to be used for DP studies were sealed in vacuum glass tubes and aged in furnaces maintained within $\pm 1 \mathrm{~K}$.

The aging temperatures for the DP reaction ranged from 900 to $1050 \mathrm{~K}$. Two sets of samples to be used for DD studies were first encapsulated in glass and preaged at 908 $\mathrm{K}$ for 271 hours and at $983 \mathrm{~K}$ for 10 hours to yield DP seams with lamellar spacings of 0.42 and $0.96 \mu \mathrm{m}$, respectively. These samples were subsequently removed from the capsules, and, owing to the rapidity of the DD reaction, dissolution heat treatments in the temperature range between 1118 and $1173 \mathrm{~K}$ had to be conducted in a lead bath. In order to avoid reaction with the molten lead, the samples were wrapped in tantalum foil.

Metallographic preparations were conducted by grinding and polishing with $0.05-\mu \mathrm{m} \mathrm{Al}_{2} \mathrm{O}_{3}$ and etching with 10 pct nitric acid in a methanol solution for 10 to 13 seconds. The morphology of the DP and DD reactions was observed through OM and SEM.

The growth rates for cells of DP reactions at various temperatures were obtained from the slopes of graphs of the true-cell width $v s$ aging time. The true-cell width was taken to be $\pi / 4$ times the average cell width, ${ }^{[28]}$ which was obtained by measuring the distance from the start of a cell to its leading edge. Fifty such measurements were made for each aged specimen. The reaction-front velocity for DD was determined from measurements of the average "ghost" image width associated with the retreating DP reaction front as a function of aging time. Fifty widths were measured for each aging temperature and time, and $\pi / 4$ times the average was then again set as the true ghost-image width similar to the case of DP reaction. The precipitate lamellar spacing for the DP reaction was measured by SEM, and the average of at least 20 experimental values was calculated.

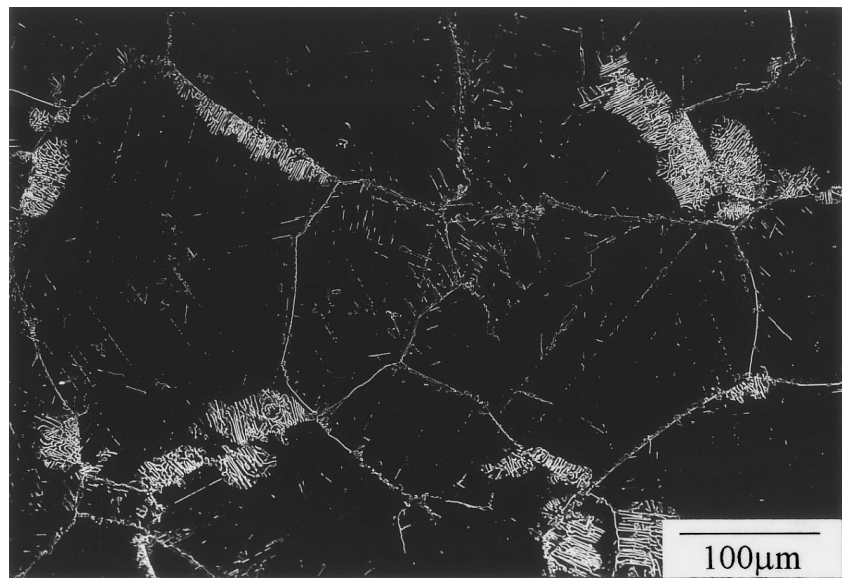

(a)

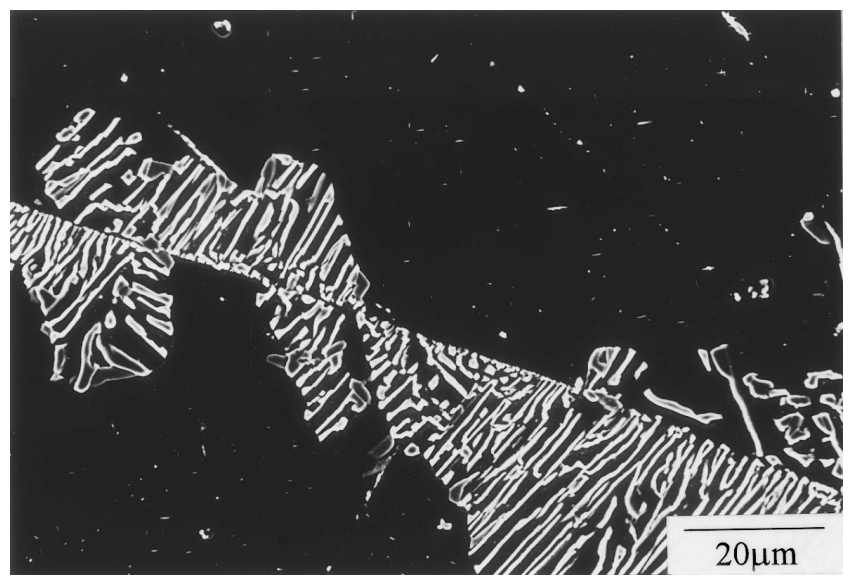

(b)

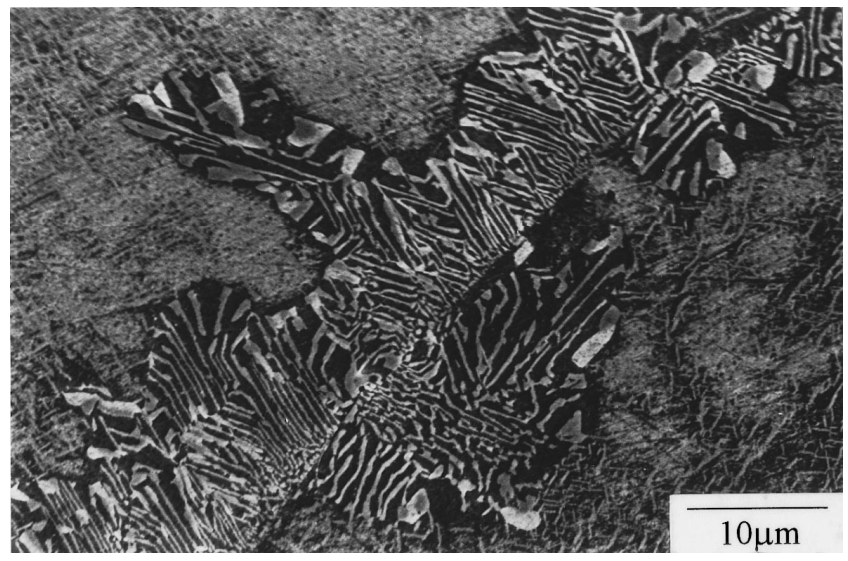

(c)

Fig. 1-Morphology of discontinuous precipitation in an Fe-8.5Al-27Mn1.0Si-0.92C alloy after aging at $983 \mathrm{~K}$ for various times: (a) $10 \mathrm{~h},(b) 10$ $\mathrm{h}$, and $(c) 72 \mathrm{~h}$

\section{RESULTS AND DISCUSSION}

After solution treatment at $1273 \mathrm{~K}$, the as-quenched Fe8.5Al-27Mn-1.0Si-0.92C specimens showed a fully austenitized phase. Having aged at the temperatures between 900 and $1050 \mathrm{~K}$, the austenite phase decomposed into lamellar precipitates at the grain boundaries, as shown in Figures 1 and 2. Along with the growth of lamellar precipitates, their reaction fronts migrated into the austenite matrix. After aging 


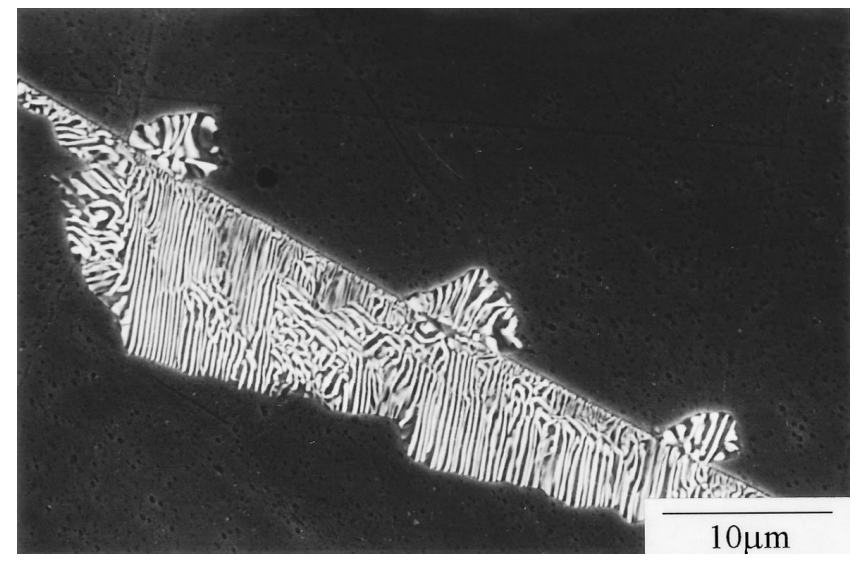

(a)

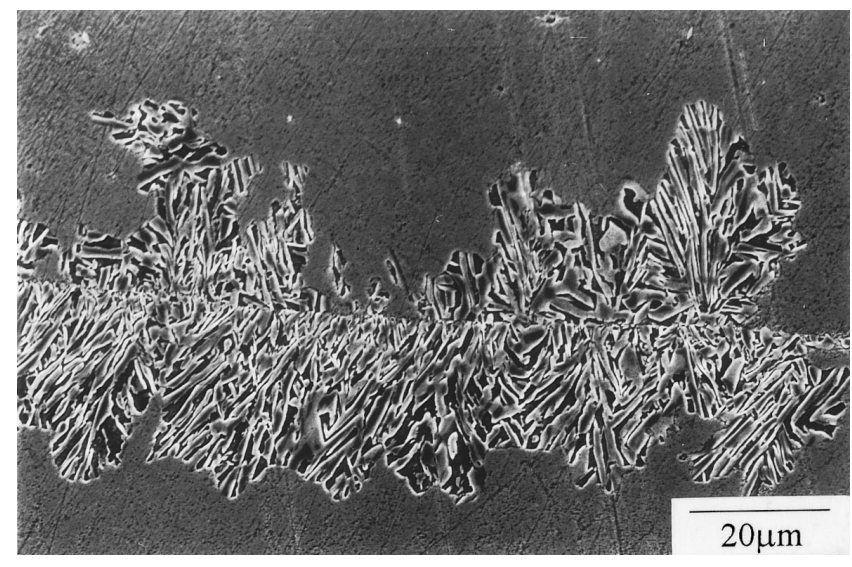

(b)

Fig. 2-Morphology of discontinuous precipitation in an Fe-8.5Al-27Mn1.0Si-0.92C alloy after aging at $908 \mathrm{~K}$ for various times: (a) $20 \mathrm{~h}$ and $(b)$ $271 \mathrm{~h}$.

at $983 \mathrm{~K}$ for 72 hours, coarse continuous precipitates appeared with a Widmannstätten structure in the austenite matrix, as shown in Figure 1(c), resulting in the inhibition of the reaction-front migration and the coarsening of the lamellar DP near the reaction front (Figure 1(d)). On the other hand, the aging treatment at $908 \mathrm{~K}$, even after 271 hours, did not cause the formation of any coarse precipitates in the austenite matrix (Figure 2(b)). In this case, the growth of lamellar DP had not been interrupted. From Figures 1 and 2 , it could also be seen that most of the lamellar DP was parallel. The lamellar spacings, as measured in Figure 3 , decreased with the decline of aging temperatures.

After further heating of the specimens, which had been partially decomposed by DP, to a temperature above 1118 $\mathrm{K}$, the lamellar DP was found to dissolve through a DD reaction, as the reaction front in between the DP and the austenite matrix migrated backwards, leaving behind an apparently inhomogeneous austenite phase (Figures 4 and 5 ). Because the redistribution of magnese and silicon atoms behind the rapidly retrogressing reaction front was incomplete, a ghost image of the former lamellar structure appeared after etching. Such metallographic ghost images have been observed in many other alloy systems exhibiting DD, ${ }^{[2,3,4]}$ providing good markings for the exact measurement of the

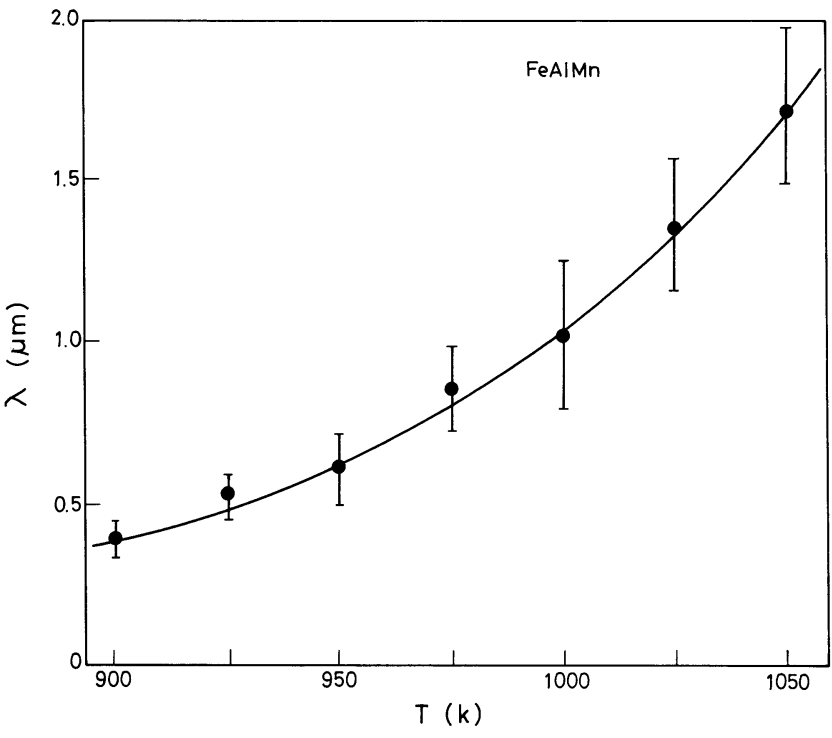

Fig. 3-Lamellar spacings for discontinuous precipitation in an $\mathrm{Fe}-8.5 \mathrm{Al}-$ $27 \mathrm{Mn}-1.0 \mathrm{Si}-0.92 \mathrm{C}$ alloy as related to aging temperatures.

dissolution velocity. For the lamellar DP formed after preaging at $983 \mathrm{~K}$ for 72 hours, with which coarse grain precipitates coexisted, the DD reaction resulted in a more homogeneous austenite matrix without the appearance of a ghost image behind the backward-migrating reaction front (Figure 4(c)). In contrast to the DD of lamellar DP, Figure 4(c) also showed that the coarse precipitates in austenite grains were preserved, which could be attributed to the much slower dissolution rate of grain precipitates through volume diffusion. After further comparison of the ghost-image widths in Figures 4 and 5, it was obvious that the finer lamellar DP, formed after preaging at $983 \mathrm{~K}$, dissolved much quicker than the coarser lamellar DP preaged at $983 \mathrm{~K}$. However, the threshold temperature required for initiating the DD reaction, in the cases of both finer and coarser lamellar DPs, was situated in the whereabouts of $1118 \mathrm{~K}$.

The migration distance of the reaction front during DP transformations, at temperatures between 900 and $1050 \mathrm{~K}$ for the aging time below 10 hours, is given in Figure 6. In the interim of the aging process, the influence of coarse grain precipitates upon the DP reaction was believed to be negligible, as evidenced by the linear relationship of the curves in Figure 6. In order to determinate the backwardmigration distance of the reaction front during the DD transformations at various temperatures ranging from 1118 to $1173 \mathrm{~K}$, the ghost-image widths were measured, as shown in Figures 7 and 8, for DD specimens preaged at $908\left(\mathrm{DD}_{1}\right)$ and $983 \mathrm{~K}\left(\mathrm{DD}_{2}\right)$, respectively. The notations on each curve also revealed a good linear relationship. The slopes of all the curves in Figures 6, 7, and 8 each evinced the reactionfront migration velocities for $\mathrm{DP}, \mathrm{DD}_{1}$, and $\mathrm{DD}_{2}$ reactions in the present $\mathrm{Fe}-8.5 \mathrm{Al}-27 \mathrm{Mn}-1.0 \mathrm{Si}-0.92 \mathrm{C}$ alloy, which were presented in Figure 9 as Arrhenius plots. As the migration rates of reaction fronts for the $\mathrm{DD}_{1}$ and $\mathrm{DD}_{2}$ reactions were placed in comparison, the finer lamellar DP formed at 908 $\mathrm{K}\left(\mathrm{DD}_{1}\right)$ was shown to dissolve about one order of magnitude quicker than the coarser lamellar DP formed at $983 \mathrm{~K}\left(\mathrm{DD}_{2}\right)$. The result could be attributed to the shorter diffusion path for the $\mathrm{DD}_{1}$ reaction of the finer lamellar $\mathrm{DP}$ preaged at a lower temperature. 


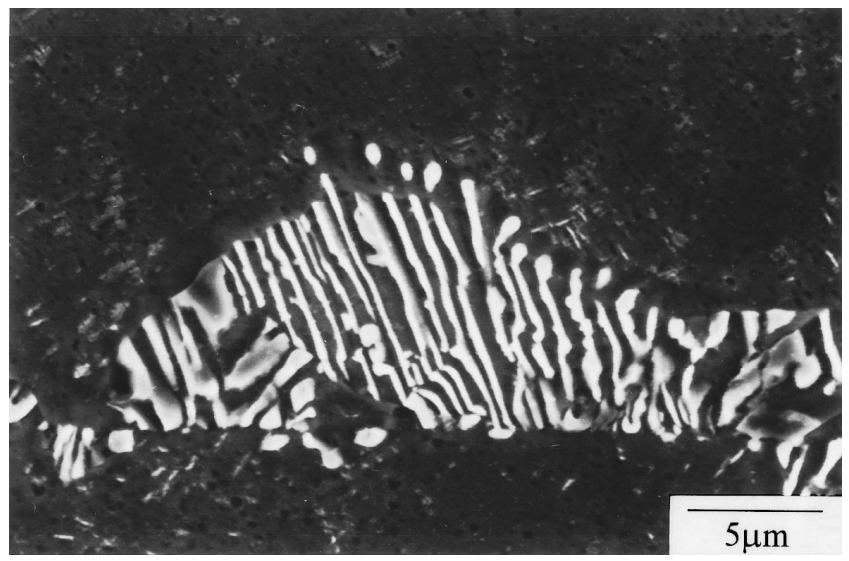

(a)

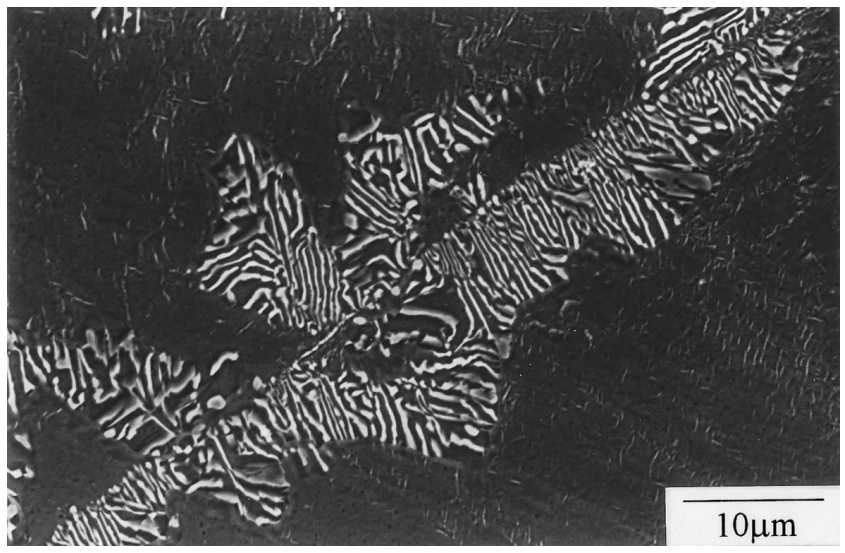

(b)

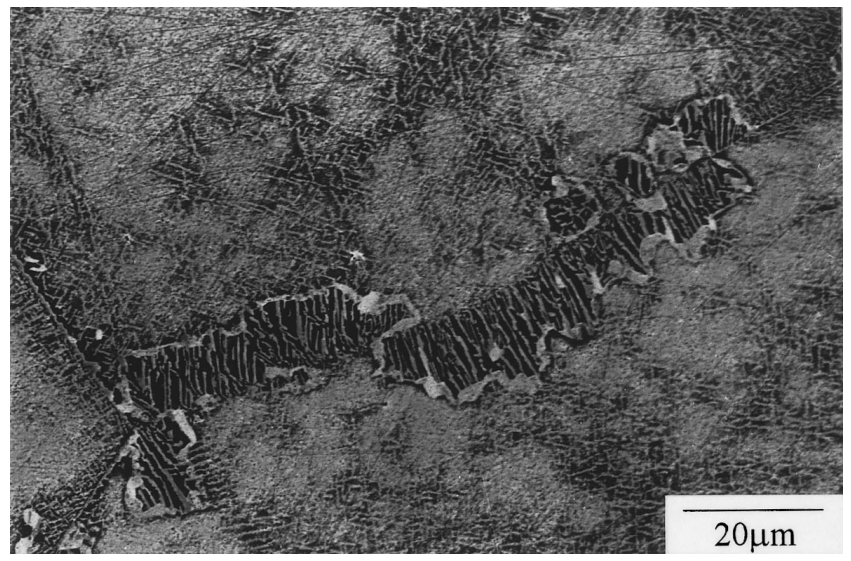

(c)

Fig. 4-Morphology of discontinuous dissolution in an Fe-8.5Al-27Mn1.0Si-0.92C alloy after pre-DP aging at $983 \mathrm{~K}$, and further DD treatments at various temperatures: $(a) \mathrm{DP}: 983 \mathrm{~K}, 10 \mathrm{~h}$, and DD: $1118 \mathrm{~K}, 180 \mathrm{~s}$; $(b)$ DP: $983 \mathrm{~K}, 10 \mathrm{~h}$, and DD: $1173 \mathrm{~K}, 60 \mathrm{~s}$; (c) DP: $983 \mathrm{~K}, 72 \mathrm{~h}$, and DD: $1118 \mathrm{~K}, 180 \mathrm{~s}$

In order to evaluate the influence of volume diffusion on the velocities of $\mathrm{DP}, \mathrm{DD}_{1}$, and $\mathrm{DD}_{2}$ reactions in this study, the effective diffusion times, $t_{\mathrm{eff}}$, as required to deplete the lamellar DP of excess magnese atoms through volume diffusion to the $\kappa$ lamellae, were calculated by applying the relationship $t_{\text {eff }}=\left(\lambda^{2} / 4 D_{v}\right)$, where $\lambda$ represented the lamellar spacings for the various reactions, and $D_{v}$ indicated the volume diffusivities of magnese in the alloy. From other studies,

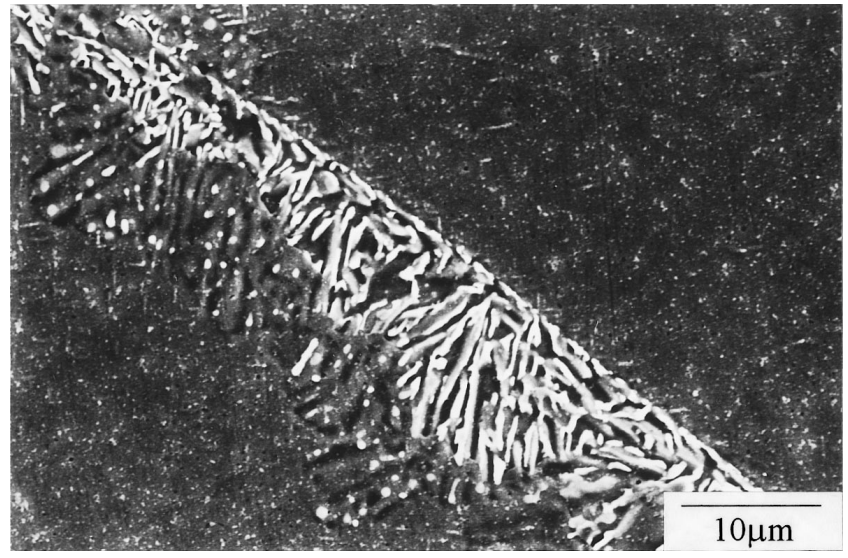

(a)

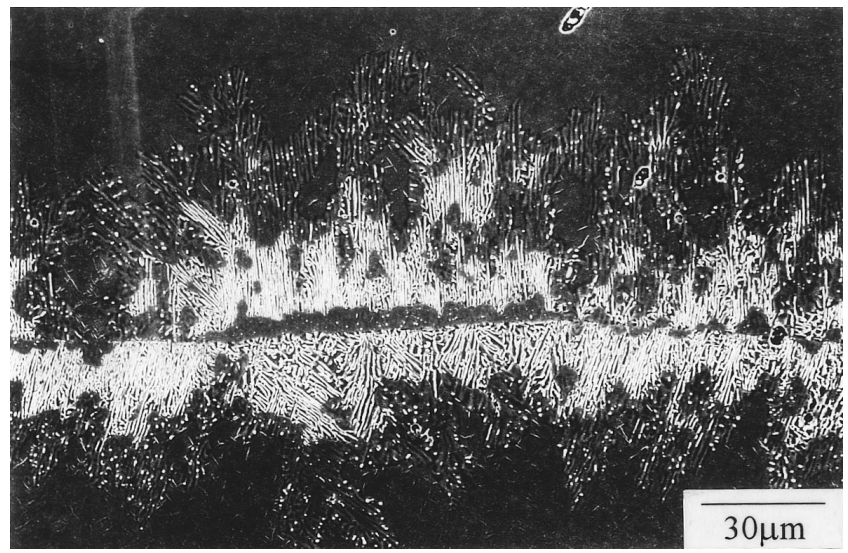

(b)

Fig. 5-Morphology of discontinuous dissolution in an Fe-8.5Al-27Mn1.0Si-0.92C alloy after pre-DP aging at $908 \mathrm{~K}$ for $271 \mathrm{~h}$, and further DD treatments at $1118 \mathrm{~K}$ for $180 \mathrm{~s}$.

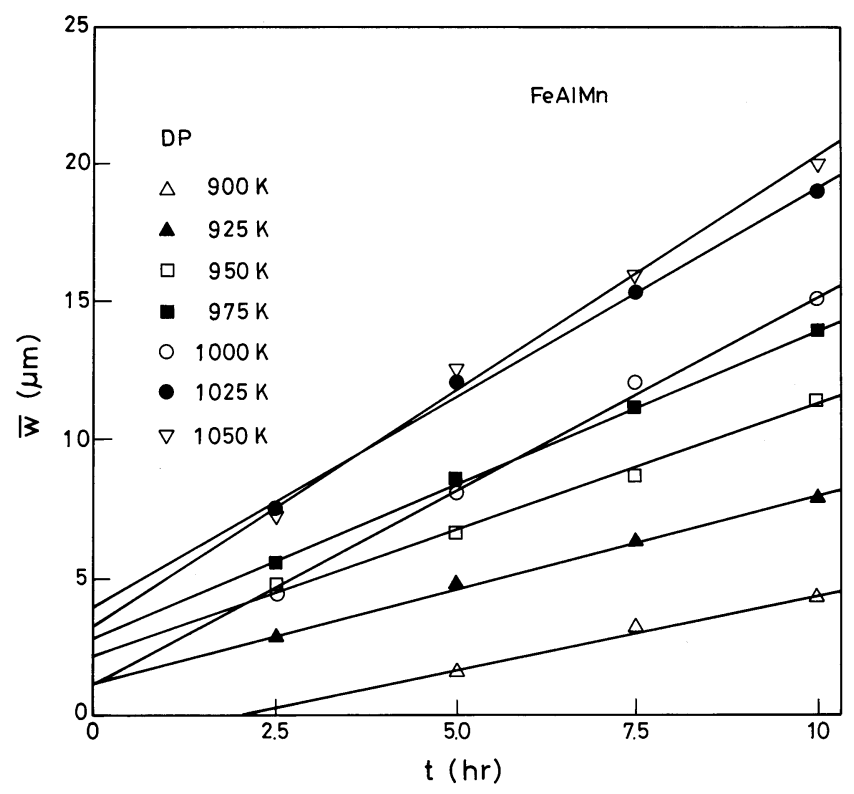

Fig. 6-Migration distance of the reaction front during the DP reaction at various temperatures as related to aging time. 


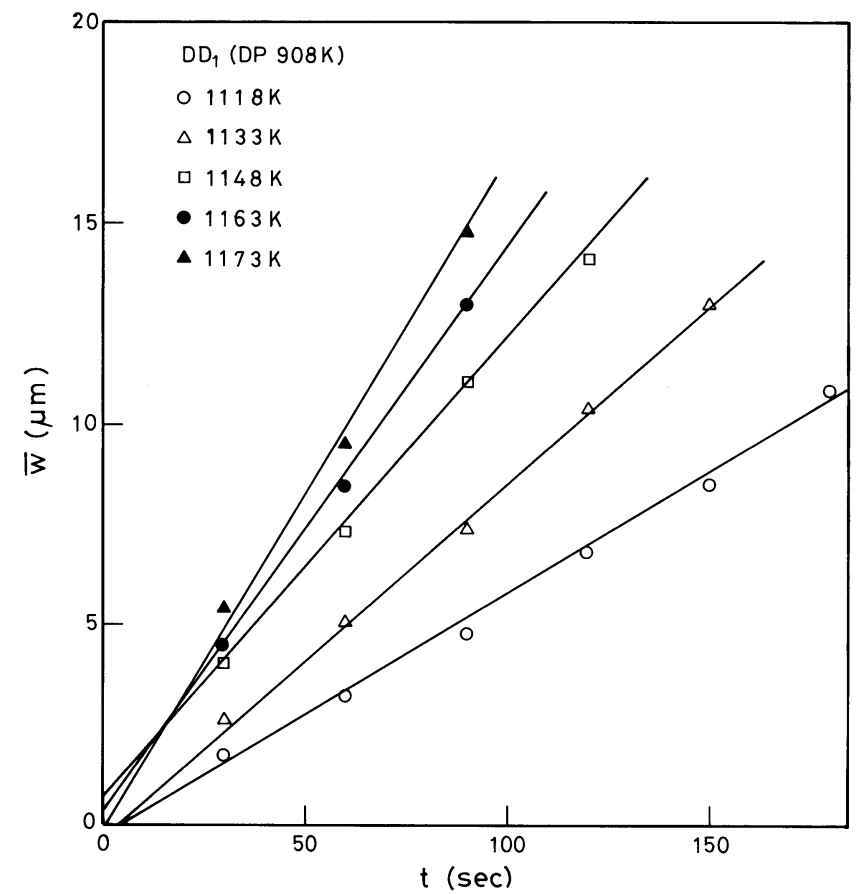

Fig. 7-Measurements of the ghost-image widths indicating the backward migration distance of the reaction front, during the $\mathrm{DD}_{1}$ reaction of the $\mathrm{DP}$ preformed at $908 \mathrm{~K}$.

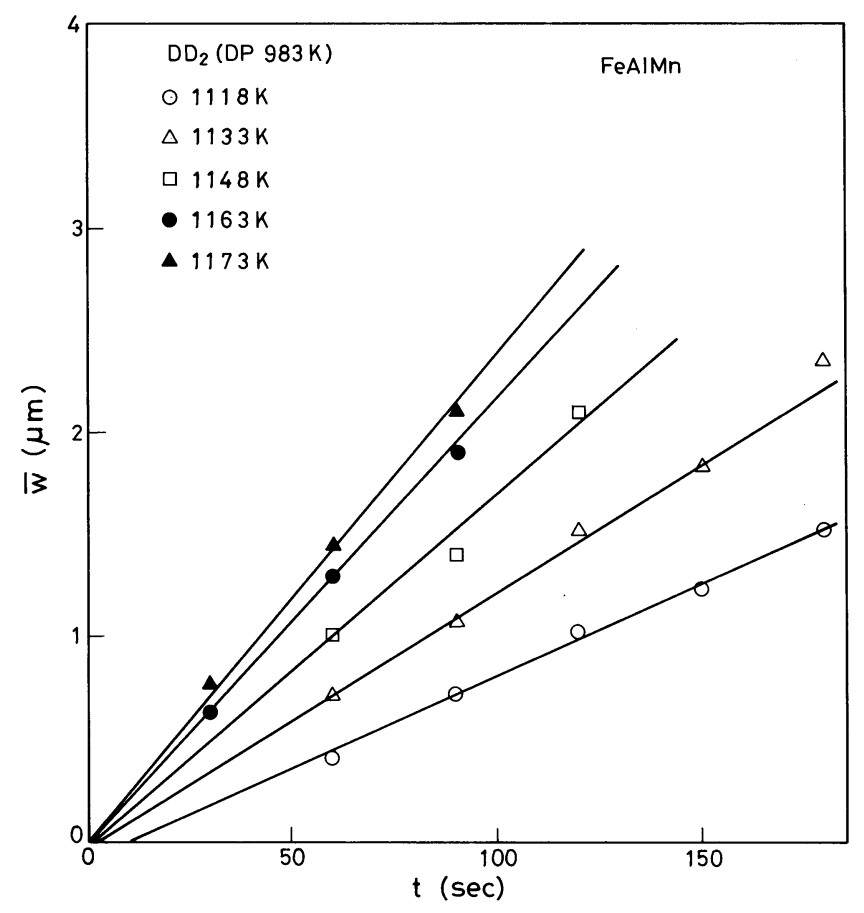

Fig. 8-Measurements of the ghost-image widths during the $\mathrm{DD}_{2}$ reaction of the DP preaged at $983 \mathrm{~K}$.

only two values of $D_{v}$ could be found, given by Lübbehus$\operatorname{sen}^{[29]}$ and Geise and Herzig ${ }^{[30]}$ for the radiotracer measurement of ${ }^{54} \mathrm{Mn}$ in $\alpha$-Fe at $993 \mathrm{~K}$ and by Larsson $^{[31]}$ for the electron probe microanalyzer measurement of $\mathrm{Mn}$ in $\gamma$ Fe at $1373 \mathrm{~K}$. This present study adopted Lübbehussen's value, ${ }^{[29]}$ and the effective volume-diffusion time related to the DP reaction at $993 \mathrm{~K}$ could thereby be estimated at

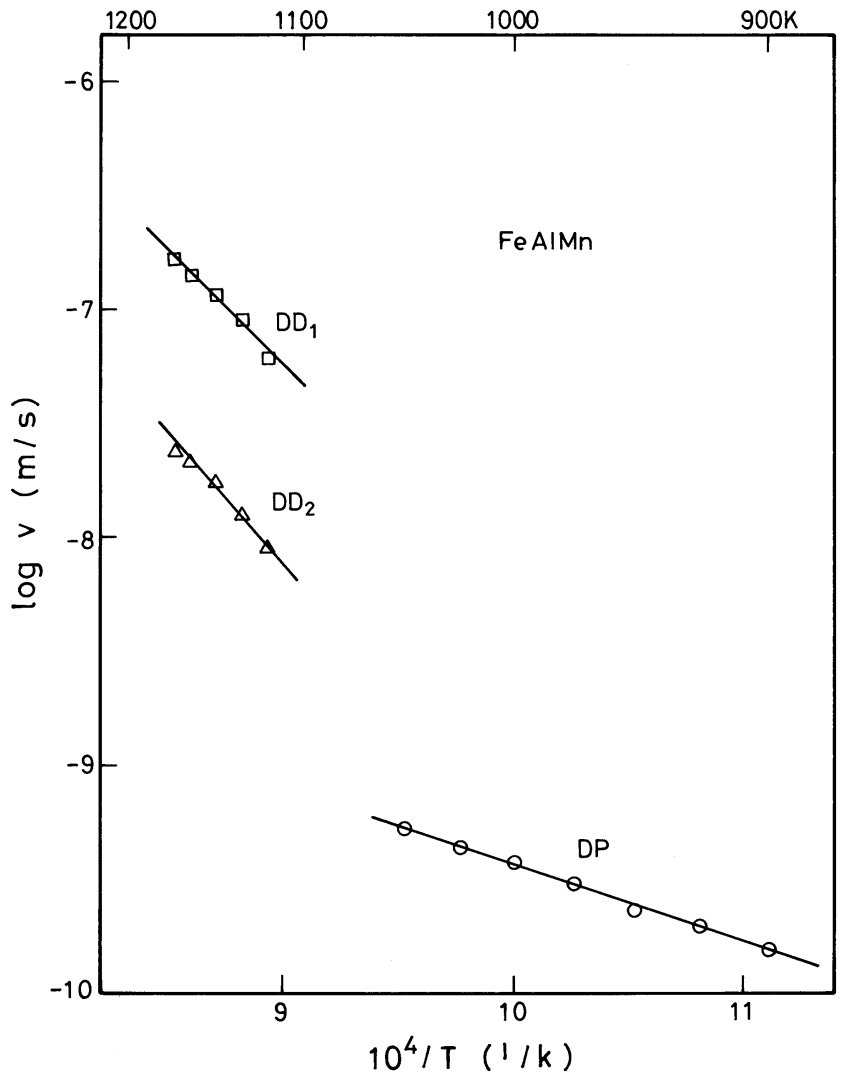

Fig. 9-Arrhenius plots of the reaction front migration rates during the $\mathrm{DP}, \mathrm{DD}_{1}$, and $\mathrm{DD}_{2}$ reactions in an Fe-8.5Al-27Mn-1.0Si-0.92C alloy.

Table I. Estimation of Effective Diffusion Times $t_{\text {eff }}$ from the Diffusion Data Provided by Hänsel et al. ${ }^{[32]}$ in the

Corresponding Temperature Range of $\mathrm{DP}, \mathrm{DD}_{1}$, and $\mathrm{DD}_{2}$, as Adopted by This Study

\begin{tabular}{ccccc}
\hline Reaction & $T(\mathrm{~K})$ & $V\left(\mathrm{~m} \cdot \mathrm{s}^{-1}\right)$ & $\lambda(\mu \mathrm{m})$ & $t_{\text {eff }}(\mathrm{s})$ \\
\hline $\mathrm{DP}$ & 900 & $1.23 \times 10^{-19}$ & 0.39 & $1.18 \times 10^{5}$ \\
& $\mid$ & $\mid$ & $\mid$ & $\mid$ \\
$\mathrm{DD}_{1}$ & 1050 & $8.52 \times 10^{-17}$ & 1.72 & $8.68 \times 10^{3}$ \\
& 1118 & $6.51 \times 10^{-16}$ & 0.42 & $6.77 \times 10^{1}$ \\
& 1173 & $2.84 \times 10^{-15}$ & $\mid$ & $\mid$ \\
$\mathrm{DD}_{2}$ & 1118 & $6.51 \times 10^{-16}$ & 0.95 & $3.46 \times 10^{2}$ \\
& $\mid$ & $\mid$ & $\mid$ & $\mid$ \\
& 1173 & $2.84 \times 10^{-15}$ & 0.95 & $7.93 \times 10^{1}$ \\
\hline
\end{tabular}

around $3.27 \times 10^{3} \mathrm{~s}(0.9$ hours $)$, thus implying that the volume diffusion had an effect on the velocity of DP. After further employment of the volume diffusivities of ${ }^{59} \mathrm{Fe}$ in Fe as reported by Hansel et al. ${ }^{[32]}$ the effective diffusion times for the corresponding reactions were calculated and listed in Table I, as an approximate evaluation of the volumediffusion effect on the kinetics of $\mathrm{DP}, \mathrm{DD}_{1}$, and $\mathrm{DD}_{2}$ reactions. It could be seen that the volume diffusion did indeed have an influence on the way the $\mathrm{DP}, \mathrm{DD}_{1}$, and $\mathrm{DD}_{2}$ reactions would proceed from the early stages on. The result implied that migration velocities of the reaction front during DP, $\mathrm{DD}_{1}$, and $\mathrm{DD}_{2}$ measured in this study should be somewhat lower than the actual values.

For the analysis of the growth kinetics of DP and DD, 


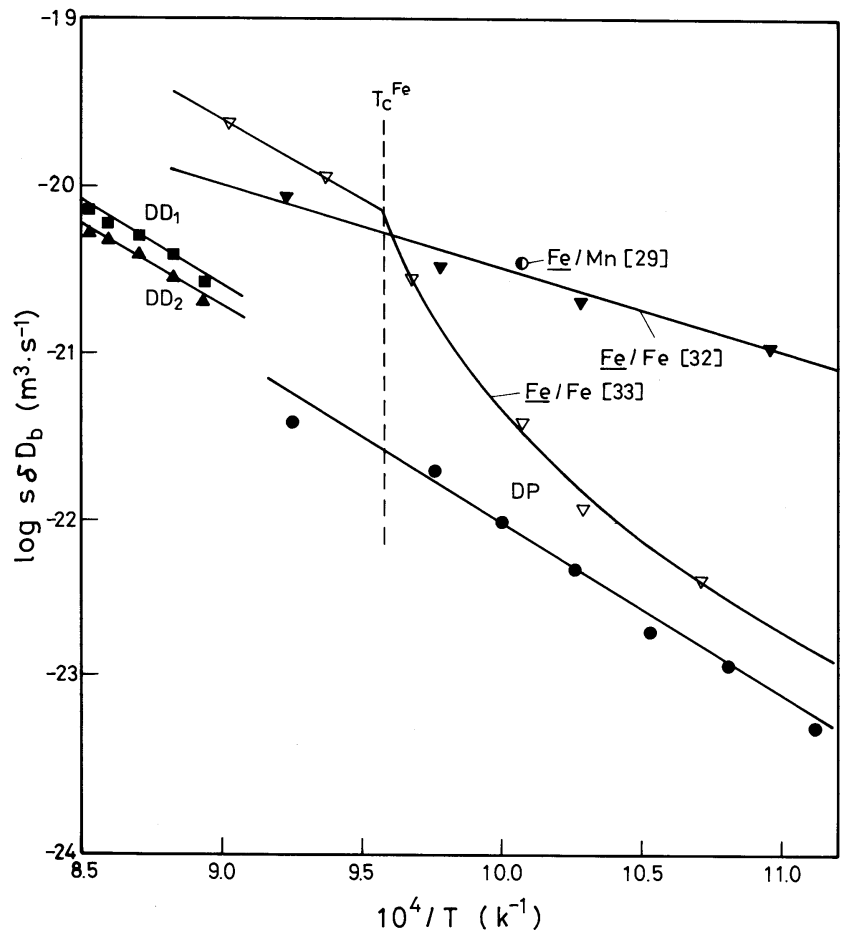

Fig. 10-Arrhenius plots of the grain boundary diffusivities estimated from the kinetics analysis of $\mathrm{DP}, \mathrm{DD}_{1}$, and $\mathrm{DD}_{2}$ reactions in an Fe-8.5Al-27Mn1.0Si-0.92C alloy. A simplified model of Aaronson and $\mathrm{Liu}^{[27]}$ is used here. Grain-boundary diffusion data for $\mathrm{Mn}$ in $\mathrm{Fe}^{[29]}$ and $\mathrm{Fe}$ in $\mathrm{Fe},{ }^{[32,33]}$ as reported in the literature are shown here for comparison.

many theoretical models have been proposed ${ }^{[20-27]}$ and generally expressed as

$$
s \delta D_{b}=A \cdot V \lambda^{2}
$$

where $V$ is the velocity of the reaction front, $D_{b}$ is the chemical diffusivity in the reaction front, $\delta$ is its thickness, $s$ is the segregation factor, ${ }^{[34]}$ and $A$ is the variable for different models. In most cases, $A$ is a function of the compositions of phases related to the reaction. Because the alloy in the current study contained multielements, most kinetics models $^{[20-26]}$ were inapplicable because of the difficulty in determining the $A$ value. To solve this problem, a simplified model of Aaronson and Liu, ${ }^{[27]}$ in which the composition terms were neglected, was employed here for an approximate estimation of the growth kinetics. According to the theory of Aaronson and Liu, the boundary diffusivity was directly related to the reaction-front velocity and the lamellar spacing, shown as follows:

$$
s \delta D_{b}=0.25 V \lambda^{2}
$$

Because at least two elements, magnese and silicon, simultaneously diffused along the reaction front during the reactions, an effective boundary diffusivity was calculated. The values were plotted out in an Arrhenius diagram, as shown in Figure 10. It was noticeable that the curves of boundary diffusivities for $\mathrm{DD}$ reactions $\left(\mathrm{DD}_{1}\right.$ and $\left.\mathrm{DD}_{2}\right)$ appeared to be extensions of the boundary diffusivity curves for DP.

As some articles ${ }^{[29,30,33]}$ mentioned, Lübbenhusen had measured the grain-boundary diffusivity of ${ }^{54} \mathrm{Mn}$ in $\alpha$-Fe at $993 \mathrm{~K}$. And certain researchers in the field, such as Hänsel et $a{ }^{\left[{ }^{[32]}\right.}$ and Herzig et al., ${ }^{[33]}$ had reported on the grainboundary diffusivities of $\mathrm{Fe}$ in $\mathrm{Fe}$ over a wide temperature
Table II. Activation Energies $Q_{b}$ Pre-Exponential Factor $\left(s \delta D_{b}\right)$ for the Grain Boundary Diffusion during the DP, $\mathrm{DD}_{1}$, and $\mathrm{DD}_{2}$ Reactions in an Fe-8.5Al-27Mn-1.0Si-0.92C Alloy; the Values Determined by Hänsel et al. ${ }^{[32]}$ for ${ }^{59} \mathrm{Fe}$ in Fe Are Also Listed Here for Comparison

\begin{tabular}{lccc}
\hline \multicolumn{1}{c}{ Systems } & $\begin{array}{c}\text { Temperature } \\
\text { Range }(\mathrm{K})\end{array}$ & $\begin{array}{c}s \delta D_{b} \\
\left(\mathrm{~m}^{3} \cdot \mathrm{s}^{-1}\right)\end{array}$ & $\begin{array}{c}Q_{b} \\
(\mathrm{~kJ} / \mathrm{mole})\end{array}$ \\
\hline $\begin{array}{l}\text { Fe-Mn-Al-Si-C } \\
(\mathrm{DP})\end{array}$ & 900 to 1050 & $2.61 \times 10^{-11}$ & 218 \\
$\begin{array}{l}\text { Fe-Mn-Al-Si-C } \\
\left(\mathrm{DD}_{1}\right)\end{array}$ & 1118 to 1173 & $4.06 \times 10^{-12}$ & 196 \\
$\begin{array}{l}\text { Fe-Mn-Al-Si-C } \\
(\mathrm{DD})\end{array}$ & 1118 to 1173 & $2.99 \times 10^{-12}$ & 196 \\
$\mathrm{Fe} / \mathrm{Fe}$ & 873 to 1083 & $1.74 \times 10^{-16}$ & 91 \\
\hline
\end{tabular}

range. These data were also given in Figure 10 for comparison, which indicated that the grain-boundary diffusivities estimated from the kinetics analysis of $\mathrm{DP}, \mathrm{DD}_{1}$, and $\mathrm{DD}_{2}$ reactions in the present $\mathrm{Fe}-8.5 \mathrm{Al}-27 \mathrm{Mn}-1.0 \mathrm{Si}-0.92 \mathrm{C}$ alloy were slightly lower than the measured grain-boundary diffusivities of $\mathrm{Mn}$ in $\mathrm{Fe}^{[29,30,33]}$ and $\mathrm{Fe}$ in Fe. ${ }^{[32,33]}$ This discrepancy might be traced to the omission of composition terms in the simplified theory of Aaronson and Liu [q.v., Eq. [2]] and the influence of volume diffusion on the reactions as well. Also, the mutual effects of various diffusing elements in this alloy and their influence on the reaction-front migration should be held responsible for the discrepancy. In the work of Herzig et al. ${ }^{[33]}$ the Arrhenius plot of the grain-boundary diffusivity for $\mathrm{Fe}$ in $\mathrm{Fe}$ was found to be inflected at the Curie temperature because of the magnetic transition, which, nevertheless, was not reflected in the estimated grain-boundary diffusion data for the DP and DD reactions in this current study.

From the Arrrhenius plots in Figure 10, the pre-exponential factor, $\left(s \delta D_{b}\right)_{0}$, and activation energy, $Q_{b}$, for DP, $\mathrm{DD}_{1}$, and $\mathrm{DD}_{2}$ could be calculated, as demonstrated in Table II. For reference, the pre-exponential factor and activation energy for the grain-boundary diffusion of $\mathrm{Fe}$ in $\mathrm{Fe}$, as reported by Hänsel et al. ${ }^{[32]}$ were also listed in the table. It was evident that the activation energies for $\mathrm{DP}, \mathrm{DD}_{1}$, and $\mathrm{DD}_{2}$ were quite similar, which implied that the atom diffusion characteristics during these grain-boundary reactions were similar, too. However, they were obviously higher than the activation energy for the grain-boundary diffusion of $\mathrm{Fe}$ in Fe. ${ }^{[32]}$ The relatively high activation energies for grainboundary diffusion during the DP and DD reactions, in the case of the alloy under study, might be attributed to the retardation of diffusion along the boundary when enriched with the dissolved component in strongly segregating systems, such as Fe-Mn ${ }^{[35]}$ and Fe-Si. ${ }^{[36]}$ The augmentation of the diffusion-retarding effect was proportional to the increase of the segregation tendency, as the segregation tendency would increase at the decrease of the temperatures. Because the activation energy represented only the temperature dependency of the grain-boundary diffusivities, the decrease of boundary diffusivity at the fall of temperatures led to a steeper Arrhenius plot and, thus, a higher activation energy.

\section{CONCLUSIONS}

The austenitized Fe-8.5Al-27Mn-1.0Si-0.92C alloy was decomposed through DP into lamellar precipitates on the 
grain boundaries during isothermal aging at temperatures ranging from 900 to $1050 \mathrm{~K}$. The lamellar spacings increased with the elevation of aging temperatures. After further heating of the specimens, which had been partially decomposed by DP at $908 \mathrm{~K}$ for 271 hours and at $983 \mathrm{~K}$ for 10 hours, to temperatures ranging from 1118 to $1173 \mathrm{~K}$, the lamellar $\mathrm{DP}$ would dissolve as a result of $\mathrm{DD}$ reactions (here, $\mathrm{DD}_{1}$ and $\mathrm{DD}_{2}$ were marked for the preaging $\mathrm{DP}$, respectively, at 908 and $983 \mathrm{~K}$ ). When a simplified model of Aaronson and Liu was adopted, the growth kinetics of $\mathrm{DP}, \mathrm{DD}_{1}$, and $\mathrm{DD}_{2}$ in this alloy could be analyzed. The estimated grain boundary diffusivities were slightly lower than the measured grain boundary diffusivities of $\mathrm{Mn}$ in $\mathrm{Fe}$, and $\mathrm{Fe}$ in $\mathrm{Fe}$, as reported in the relevant article. The activation energies for grain boundary diffusion calculated from the kinetics analysis of $\mathrm{DP}, \mathrm{DD}_{1}$, and $\mathrm{DD}_{2}$ were 218, 196, and $196 \mathrm{~kJ} / \mathrm{mole}$, respectively.

\section{REFERENCES}

1. W. Gust: Phase Transformations, Spring Residential Conf., Apr. 4-7, 1979, University of York, York, England, The Chameleon Press, London, 1979.

2. P. Zieba and W. Gust: Int. Met. Rev., 1998, vol. 43, pp. 70-97.

3. K.N. Tu and D. Turnbull: Metall. Trans., 1971, vol. 2, pp. 2509-15.

4. T.H. Chuang, R.A. Fournelle, W. Gust, and B. Predel: Trans. Jpn. Inst. Met., 1986, vol. 27, pp. 609-16.

5. C.J. Altstetter, A.P. Bentley, J.W. Fourie, and A.N. Kirkbride: Mater. Sci. Eng., 1986, vol. 82, pp. 13-25.

6. S.K. Banerji: Met. Progr., 1978, vol. 113, pp. 59-62.

7. V.G. Rivlin: Int. Met. Rev., 1983, vol. 28, pp. 309-39.

8. P.J. James: J. Iron Steel Inst., 1969, Jan., pp. 54-57.

9. G.S. Krivonogov, M.F. Alekseyenko, and G.G. Solovyeva: Fiz. Met. Metalloved., 1975, vol. 39 (4), pp. 775-81.
10. N.A. Stochak and A.G. Darchinskaya: Fiz. Met. Metalloved., 1977, vol. 44 (2), pp. 373-80.

11. K. Sato, K. Tagawa, and Y. Inoue: Metall. Trans. A, 1990, vol. 21A, pp. 5-11.

12. J.G. Duh, S.H. Huarng, and C.M. Wan: Chin. J. Mater. Sci., 1984, vol. 16A (1), pp. 14-24.

13. C.Y. Chao, C.N. Hwang, and T.F. Liu: Scripta Metall. Mater, 1993, vol. 28, pp. 109-14.

14. W.K. Choo and K.H. Han: Metall. Trans. A, 1985, vol. 16A, pp. 5-10.

15. K.H. Han and W.K. Choo: Metall. Trans. A, 1989, vol. 20A, pp. 205-14.

16. C.N. Hwang, C.Y. Chao, and T.F. Liu: Scripta Metall. Mater, 1993, vol. 28, pp. 263-68.

17. C.Y. Chao and T.F. Liu: Metall. Trans. A, 1993, vol. 24A, pp. 1957-63.

18. C.Y. Chao, C.N. Hwang, and T.F. Liu: Scripta Mater, 1996, vol. 34, pp. $75-81$.

19. C.Y. Chao and T.F. Liu: Scripta Metall., 1991, vol. 25, pp. 1623-28

20. D. Turnbull: Acta Metall., 1955, vol. 3, pp. 55-63.

21. J.W. Cahn: Acta Metall., 1959, vol. 7, pp. 18-28.

22. J.M. Shapiro and J.S. Kirkaldy: Acta Metall., 1968, vol. 16, pp. 1239-52.

23. J. Petermann and E. Hornbogen: Z. Metallkd., 1968, vol. 59, pp. 814-22.

24. B.E. Sundquist: Metall. Trans., 1973, vol. 4, pp. 1919-34.

25. M. Hillert: Acta Metall., 1982, vol. 30, pp. 1689-96.

26. A. Bögel and W. Gust: Z. Metallkd., 1988, vol. 79, pp. 296-306.

27. H.I. Aaronson and Y.C. Liu: Scripta Metall., 1968, vol. 2, pp. 1-7.

28. R. Luck: Z. Metallkd., 1975, vol. 66, pp. 488-91.

29. R. Lubbehusen: Diploma Thesis, University of Munster, Munster Germany, 1984.

30. J. Geise and C. Herzig: Z. Metallkd., 1985, vol. 76, pp. 622-26.

31. L.E. Larsson: Mater. Sci. Eng., 1975, vol. 9, pp. 241-44.

32. H. Hänsel, L. Stratmann, H. Keller, and E.J. Grabke: Acta Metall., 1985, vol. 33, pp. 659-65.

33. C. Herzig, P. Neuhaus, and J. Geise: Int. Proc. Solute-Defect Interaction: Theory and Experiment, S. Saimoto, G.R. Purdy, and G.V. Kidson, eds., Pergamon Press, Toronto, 1986, p. 271.

34. G.B. Gibbs: Phys. Status Solidi, 1966, vol. 16, pp. k27-k29.

35. E.D. Hondros and M.P. Seah: Int. Met. Rev., 1977, vol. 22, pp. 262-301.

36. M.P. Seah: Acta Metall., 1980, vol. 28, pp. 955-62. 